EVS25

Shenzhen, China, Nov 5-9, 2010

\title{
SIM-Drive \\ -About the efficient electric vehicle spread strategy by open source method-
}

Mamoru Shiikiı, Hiroshi Shimizuı

1 Graduate School of Media and Governance, Keio University

5322 Endo Fujisawa City, Kanagawa/ Japan

\begin{abstract}
This proposal describes new electric vehicles (EVs), whose development has been led by SIM-Drive Corporation. Presently, Dr.Hiroshi Shimizu(President of SIM-Drive Corporation) has completed eight prototype vehicles; he is now developing the next prototype that is comparable to the current models of EVs that are available on the market.The development technique is a open source method.
\end{abstract}

Keywords - "SIM-Drive" "open source" "in-wheel motor" "Hiroshi Shimizu"

\section{1. strategy by open source method}

\subsection{Establishment and Activities of SIM-Drive}

SIM-Drive Representative Hiroshi Shimizu has been developing EVs mainly in Keio University for over 30 years,completing eight innovative cars. SIM-Drive Corporation was established on August 20, 2009, in order to popularise and promote this technology around the world, and to replace petrol vehicles with EVs (Figure 1).

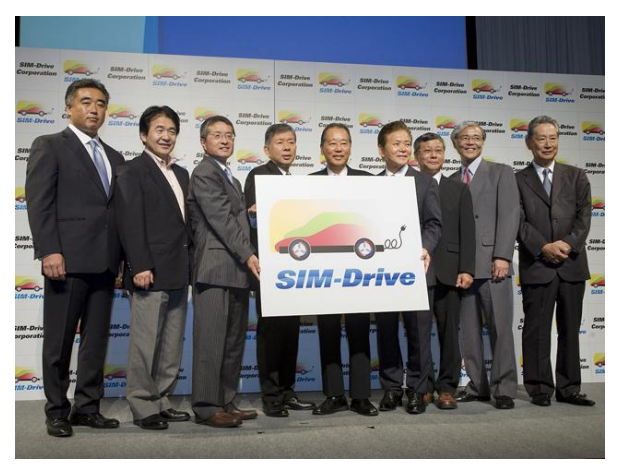

Figure 1: Appearance of establishment press release

In order to develop this technology into a global business from a market-in and user-oriented approach, rather than a product-oriented philosophy, SIM-Drive Corporation invited nationally known figures who have practiced "business management from the perspectives of consumers." The management team includes the following: Soichiro Fukutake, Chairman of Benesse Holdings, Inc., one of Japan's most recognised executives, who has expanded Japan's largest educational industry, Berlitz International, Inc., as well as Simul International, Inc., and other prominent companies; Kenichi Hattori, Chief Executive Officer, and Chairman of Gulliver International, Inc., the Japan's largest car dealer that handles 300000 used cars each year, sells 60000 used cars online, and established a new business model for users;Hiroshi Fujiwara, Chief Executive Officer, one of the most successful IT entrepreneous in Japan. Fujiwara, before joining SIM-Drive Corporation, set up a company called Nano-Optonics Energy that supports science and technology for improving the global environment. The advisors include: Professor Jun Murai, Dean of the Faculty of Environment and Information Studies of Keio University, and Nobuyuki Idei, former Chief Executive Officer of Sony. This team consists of the renowned people of Japan and has been deeply involved in the process of developing standard models and technology 
for EVs.

SIM-Drive Corporation believes in the effectiveness of user-oriented perspectives. Therefore the Corporation emphasizes technology that makes EV promotion easy through the standardisation of battery sizes and outlet plugs. SIM-Drive also delivers EV bodies and batteries separately.

\subsection{SIM-Drive Corporation's Technology}

Representative Director Hiroshi Shimizu has developed EV technology based on the belief that technology changes from low efficiency to high efficiency, from being hard to use to easy to use, and from the complicated to the simple. One of the results is Eliica[1] completed in 2005 years (Figure 2,3,4).

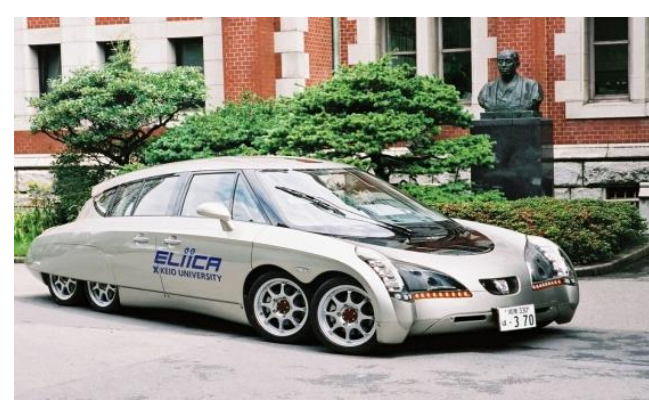

Figure 2: Eliica Externals

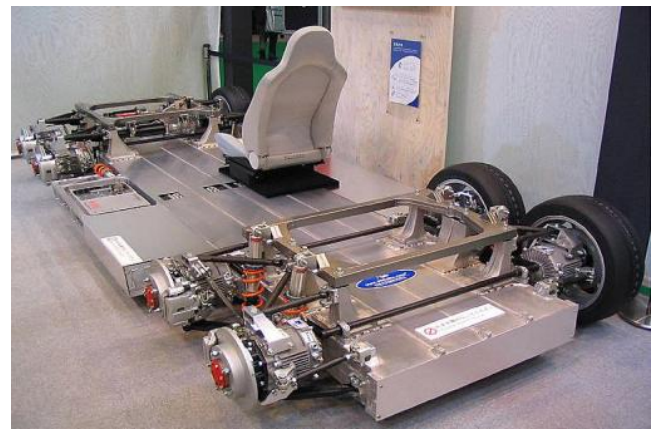

Figure 3: Eliica 8WD Internal structure

\begin{tabular}{|c|c|}
\hline Built & 2004 \\
\hline Total length & $5.10 \mathrm{~m}$ \\
\hline Total width & $1.90 \mathrm{~m}$ \\
\hline Total height & $1.365 \mathrm{~m}$ \\
\hline Seating capacity & 4 \\
\hline Vehicle weight & $2400 \mathrm{~kg}$ \\
\hline Range per charge & $300 \mathrm{~km}$ \\
\hline $\begin{array}{l}\text { Battery output and } \\
\text { voltage }\end{array}$ & $55 \mathrm{kWh} / 328 \mathrm{~V}$ \\
\hline Maximum output & $75 \mathrm{~kW} \times 8$ \\
\hline 0-100 $\mathrm{m}$ acceleration & $4.1 \mathrm{sec}$ \\
\hline Top speed & $370 \mathrm{~km} / \mathrm{h}$ \\
\hline
\end{tabular}

Figure 4: Eliica Performance table

The technical features of this vehicle are:

(1) an in-wheel motor installed in wheels (Figure 5);

(2) a built-in frame for components that holds batteries, speed controllers, etc. within a hollow but solid frame installed under the floor(Figure 6);

(3) a tandem-wheel suspension with eight-wheel drive, obtained by dividing a large wheel into two wheels.

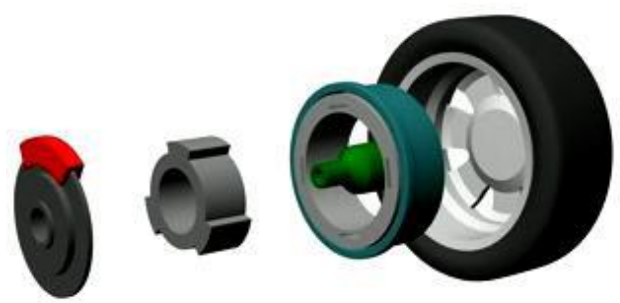

Figure 5: "by SIM-Drive" in -wheel Motor

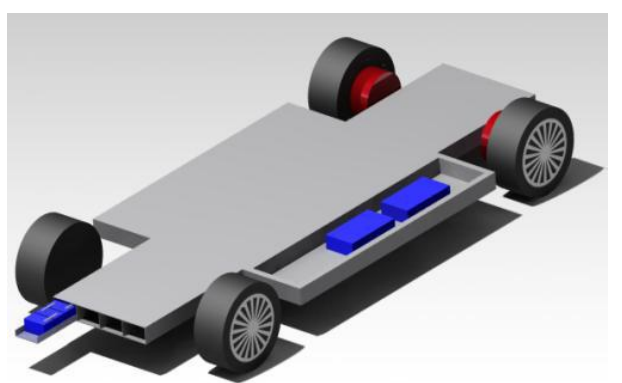

Figure 6: Platform by SIM-Drive component Built-In Platform

Such technology results in highly efficient cars, with ability to reach $370 \mathrm{~km}$ per hour, and spacious car compoartments[2].

SIM-Drive Corporation successfully applies the above 
technology in order to achieve high acceleration performance, spacious car compartments, a comfortable ride, and a long range.

\subsection{SIM-Drive Corporation's Business Model}

SIM-Drive Corporation aims to quickly popularise its unique technology for EVs worldwide. Therefore, the Corporation is not a manufacturer dealer that produces and sells automobiles but rather a partner consultant for development that provides the Corporation's technology worldwide to companies interested in EVs.

SIM-Drive Corporation first solicits investments from companies, municipalities, and governments that are interested in EVs, and then builds an advanced development prototype. The prototype is then shared with a client company as a reference implementation before the technology is transferred to them. SIM-Drive Corporation transfers in-wheel motor technology as well as technology related to the wheeled platform structure, which combines an in-wheel motor and a built-in frame for components.(Figure 7)

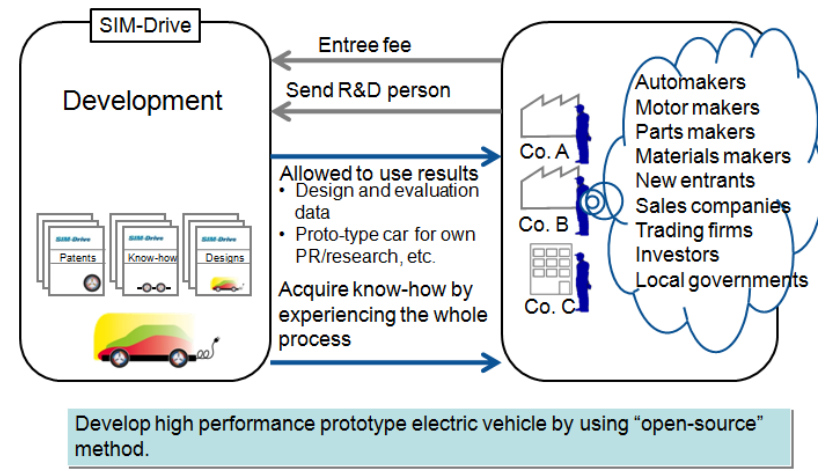

Figure 7: SIM-Drive Development Business Model

The cost of participating in an advanced development project is 20 million JPY per organisation. A participating organisation will in return receive the best of the latest electronic vehicle technology.

In terms of technology transfer, if a participating organisation mass-produces a completed model, the organisation can have access to all the technology developed by SIM-Drive Corporation with a transfer fee of 300 million
JPY and a royalty fee of $1 \%$ of the sales price for the first five years.

If a participating organisation adopts a wheeled platform structure developed by SIM-Drive Corporation, the transfer fee will be 200 million JPY with a royalty fee of $2 \%$. If an in-wheel motor is adopted, a transfer fee will be 100 million JPY with a royalty fee of $3 \%$.

\subsection{Business Plan}

Based on the business model described in the preceding chapter, SIM-Drive Corporation started the first advanced development project in January 2010, which will last for one year and three months(Figure 8).

\begin{tabular}{|c|c|c|c|c|}
\hline & 2010 & 2011 & 2012 & 2013 \\
\hline $\begin{array}{l}1^{\text {st }} \text { Prototype } \\
\text { Project }\end{array}$ & $\begin{array}{c}\text { Prototype } \\
\text { Development }\end{array}$ & \multicolumn{2}{|c|}{ Technology transfer and consulting } & Production \\
\hline $\begin{array}{l}2^{\text {nd }} \text { Prototype } \\
\text { Project }\end{array}$ & & $\begin{array}{c}\text { Prototype } \\
\text { Development }\end{array}$ & Technology tra & Ir and consulting \\
\hline $\begin{array}{l}3^{\text {rd }} \text { Prototype } \\
\text { Project }\end{array}$ & & & $\begin{array}{c}\text { Prototype } \\
\text { Development }\end{array}$ & $\begin{array}{l}\text { Technology } \\
\text { transfer and } \\
\text { consulting }\end{array}$ \\
\hline
\end{tabular}

Figure 8: Schedule of Developing Prototype Model and Commercial Model for Mass Production

The goal of this project is to build an advanced development prototype for an EV, which will be commercialised and mass-produced in 2013. SIM-Drive Corporation is planning to manufacture the following models: A Ground-up model (a model to be developed from scratch such as an EV) geared towards mass-production (Figure 9)

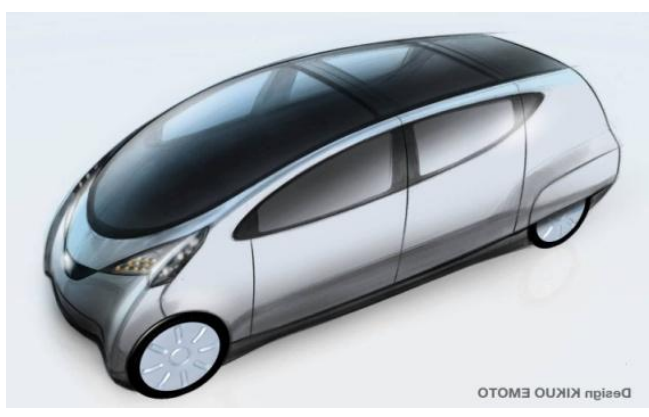

Figure 9: An Image of a Ground-up Vehicle

34 organisations, both within and outside of Japan, have expressed interest in this project(Figure 10). 


$\begin{array}{ll}\text { Benesse Holdings, Inc. } & \text { Nishimikawa Development Inc. } \\ \text { Dynax Corporation } & \text { Nippon Telegraph and Telephone East Corp. } \\ \text { IHI Corporation } & \text { Olympus Corporation } \\ \text { Inoue Manufacturing Co., Ltd. } & \text { Okayama Prefectural Government } \\ \text { Iriso Electronics Co., Ltd } & \text { Pioneer Corporation } \\ \text { Isuzu Motors Limited } & \text { Sanden Corporation } \\ \text { Japan Aviation Electronics Industry, Ltd. } & \text { Serio Corporation } \\ \text { Kureha Corporation } & \text { Tanaka Kikinzoku Group } \\ \text { Mitsubishi Corporation } & \text { TECOElectric \& Machinery Co., Ltd. } \\ \text { Mitsubishi Motors Corporation } & \text { Teikoku Piston Ring Co., Ltd. } \\ \text { Mitsui \& Co., Ltd. } & \text { THK Co., Ltd. } \\ \text { Mitsuiwa Corporation } & \text { Tokyo Electric Power Company } \\ \text { Nano-Optonics Energy, Inc. } & \text { Totoku Toryo Co., Ltd. } \\ \text { Nikkan Industries Co., Ltd. } & \text { Tottori Prefectural Government } \\ & \text { (Alphabetical order) }\end{array}$

Figure 10: Companies/Organizations Participating the 1st

Prototype Project

In particular, a noteworthy participant is Mitsubishi Motors

Corporation, which released the world's first mass-produced EV “iMiEV(Figure 11)" in 2009. and two Japanese municipalities Okayama Prefecture and Tottori Prefecture will participate in this project.

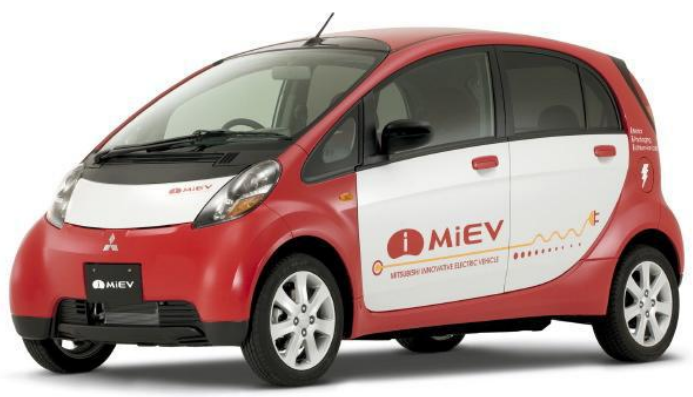

Figure 11: iMiEV (2009 Mitsubishi Motors Japan)

Having announced that it would promote the development and popularisation of EVs for the long-term future of the company, Mitsubishi Motors Corporation is considered to be the front-runner in the area of EVs due to their development and popularisation of these vehicles. $\mathrm{MMEV}$ is an EV based on the Central Motor model type; however, because the company has a history of pursuing development based on the In-wheel Motor technology, it has decided that the next model of $\mathrm{MMiEV}$ will adopt an in-wheel motor mechanism. By linking the accumulated technology of SIM-Drive Corporation and Mitsubishi Motors Corporation's know-how of test capability and mass-production capacity, the strategy explained in this proposal becomes closer to realisation.

The participation of Okayama Prefecture and Tottori
Prefecture presents a groundbreaking new model for development local industries. The Ministry of Economy, Trade, and Industry in Japan has been promoting a policy to "increase local manufacturing capability." SIM-Drive Corporation believes that a model in which the national government becomes the centre of the policy, while companies in each prefecture actively learn the latest technology for applying them to their own businesses, will be a program worth noting in Japan as well as in the world.

\subsection{Schedule}

SIM-Drive Corporation made strategic road maps for business planning until 2020. Based on the following road map, SIM-Drive Corporation expects to develop and offer more than 10 million new EVs and more than 4.25 million EVs modified from existing cars(Figure 12), which totals 14.25 million EVs in 2020. In this scenario, it forecasts the annual revenue of 22.69 trillion JPY and the annual profit of 226.9 billion JPY.

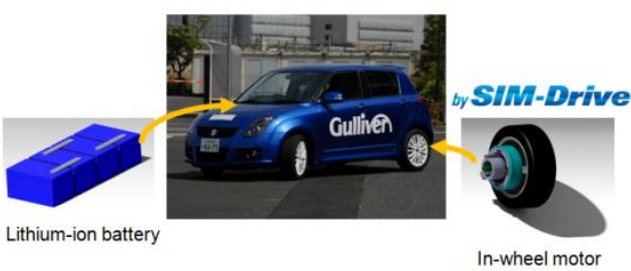

Figure 12: Internal combustion engine cars are readily convertible to electric vehicles

\section{Conclusion}

The requirements of the 21 st century traffic scene are accuracy, safety, and the lessening of environmental burden.

SIM-Drive Corporation aims to establish

low-environmental impact infrastructure by popularising EVs based on the Corporation's primary technology "In-wheel Motors." In order to achieve this, SIM-Drive Corporation is dedicated not only to technology and product development but also to consultations provided to other 
automobile and related companies. SIM-Drive Corporation promotes activities for the general public, and education on the next generation human resources in collaboration with Benesse Holdings, Inc. SIM-Drive Corporation has determined to utilise the grants that it receives in order to communicate with consumers about the process of product development, to pursue the highest level of professionalism in every field of business, and to contribute to global environmental measures with the latest technology.

SIM-Drive Corporation is:

- developing and providing environmentally friendly vehicles, and is committed to making the world a better place to live for children and families.

- creating "the next industry" to save Japan and the world. - providing education that leads to a "better life" in order to "nurture human resources."

To achieve the above philosophy, SIM-Drive Corporation will encourage industries, governments, academics, and the global society as a whole; value each technology, each consumer, and each working opportunity with our partners; constantly examine what is expected from the Corporation and what we need to achieve; and continue to fulfill our responsibilities.

\section{References}

[1] Hiroshi Shimizu, Kikuo Emoto, Kiyomoto Kawakami, Eliica, an 8-Wheel Drive Electric Vehicle, Journal of Society of

Automotive Engineers of Japan 61(9), 83-88, 2007-09-01

[2] Hiroshi Shimizu, Tadashi Takano, Kikuo Emoto, Kiyomoto Kawakami, Electric Vehicles for the Future, Technical report of IEICE. Energy engineering in electronics and communications(The Institute of Electronics, Information and Communication Engineers) 106(562), 9-14, 2007-02-23

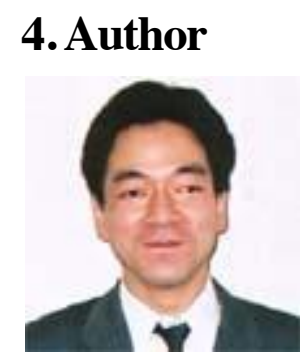

\section{Mamoru Shiiki}

Doctor's course

Graduate School of Media and Governance, Keio University

Tel:+81-44-201-1014

Fax:+81-44-599-6444

Email:shiiki@sim-drive.com

URL:http://www.sim-drive.com/

Director of Administration Office

Association for the Promotion of Electric Vehicles

Specialization: Electric Vehicle, Marketing, strategy

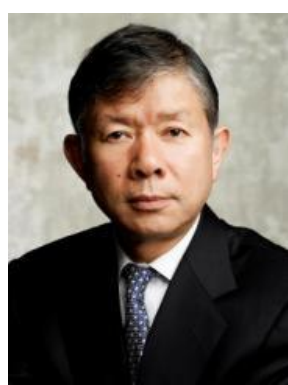

\section{Hiroshi Shimizu}

Professor Faculty of Environment and Information Studies Graduate School of Media and Governance

Keio University

Tel:+81-44-580-1565

Fax: +81-44-580-1435

Email: hiros@sfc.keio.ac.jp

URL: http://www.eliica.com/

Specialization: Environmental Technology, Electric Vehicle 